\title{
Preparation and application of reduced graphene oxide as the conductive material for capacitive deionization
}

\author{
Ayu Tyas Utami Nugrahenny ${ }^{1,2}$, Jiyoung Kim ${ }^{1,2}$, Sang-Kyung Kim ${ }^{1,2}$, Dong-Hyun Peck ${ }^{2}$, Seong-Ho Yoon ${ }^{3}$ \\ and Doo-Hwan Jung ${ }^{1,2, \$}$ \\ ${ }^{1}$ Advanced Energy Technology, University of Science and Technology, Daejeon 305-350, Korea \\ ${ }^{2}$ Fuel Cell Research Center, Korea Institute of Energy Research, Daejeon 305-343, Korea \\ ${ }^{3}$ Institute for Materials Chemistry and Engineering, Kyushu University, Kasuga, Fukuoka 816-8580, Japan
}

\section{Article Info \\ Received 8 November 2013 \\ Accepted 7 December 2013 \\ *Corresponding Author \\ E-mail: doohwan@kier.re.kr Tel: $+82-42-860-3577$ \\ Open Access \\ DOI: http://dx.doi.org/ \\ 10.5714/CL.2014.15.1.038 \\ This is an Open Access article distributed under the terms of the Creative Commons Attribution Non-Commercial License (http://creativecommons.org/licenses/ by-nc/3.0/) which permits unrestricted non-commercial use, distribution, and reproduction in any medium, provided the original work is properly cited.}

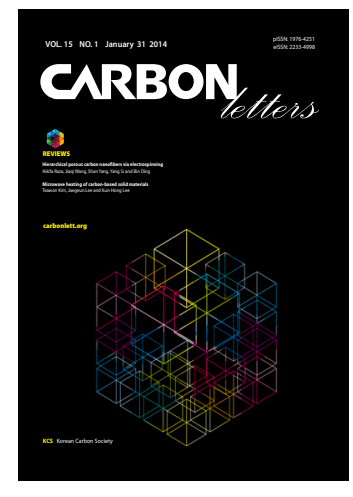

http://carbonlett.org

pISSN: $1976-4251$

elSSN: 2233-4998

Copyright $\odot$ Korean Carbon Society

\begin{abstract}
This paper reports the effect of adding reduced graphene oxide (RGO) as a conductive material to the composition of an electrode for capacitive deionization (CDI), a process to remove salt from water using ionic adsorption and desorption driven by external applied voltage. RGO can be synthesized in an inexpensive way by the reduction and exfoliation of GO, and removing the oxygen-containing groups and recovering a conjugated structure. GO powder can be obtained from the modification of Hummers method and reduced into RGO using a thermal method. The physical and electrochemical characteristics of RGO material were evaluated and its desalination performance was tested with a CDI unit cell with a potentiostat and conductivity meter, by varying the applied voltage and feed rate of the salt solution. The performance of RGO was compared to graphite as a conductive material in a CDI electrode. The result showed RGO can increase the capacitance, reduce the equivalent series resistance, and improve the electrosorption capacity of CDI electrode.
\end{abstract}

Key words: reduced graphene oxide, graphite, conductive material, capacitive deionization

\section{Introduction}

Water recovery research has attracted great attention due to the existing global water crises. One of the key tools to resolve a future global water crises is continued research into methods that will provide low-cost and high efficiency desalination. Most existing desalination technologies such as reverse osmosis and distillation require a great deal of energy, so it is imperative to find more energy efficient methods to desalinate water [1].

Electrosorption has been shown to be the most promising method for potential future application, for desalinating solutions of low-to-moderate ionic strength [2]. The basic concept of electrosorption is to use an external applied potential to force charged ions in an electrolyte solution toward oppositely charged electrodes, making an electrical double layer (EDL) region. This salt removal technology has been known as capacitive deionization (CDI). The ability of the CDI process to operate at low voltage and without chemical waste has made it a promising technology for overcoming the drawbacks of other desalination technologies.

The CDI unit cell mainly consists of electrodes, current collectors, and a spacer. The correct choice of electrode material is important because its ability to adsorb ions affects the performance of the salt removal process. Carbon, with its wide variety of available forms and porosity, has been found to be the electrode material of choice for CDI and other electrosorption processes [3]. Many studies have been carried to investigate the electrochemical behavior of many kinds of carbons for application as electrosorption electrodes [4-8].

Among the various forms of carbon materials, activated carbon (AC) has been widely used as the main electrode material for CDI, due to its high surface area $\left(>1000 \mathrm{~m}^{2} \mathrm{~g}^{-1}\right)$ and 
extensive micropores (pore size $<2 \mathrm{~nm}$ ) $[9,10]$. The main problems of AC electrodes have been their the low electrode conductivity due to the low accessibility of micropores to the aqueous solution [11] and the weak physical bonding of AC [12].

To manufacture CDI electrodes with good particle-to-particle contact between the small carbon grains, AC powder is combined with a polymeric binder, such as polytetrafluoroethylene or polyvinylidene fluoride (PVdF). However, the amount of polymeric binder used must be limited (5-10\%) because the use of polymeric binder increases internal resistance and may block some of the carbon pores, resulting in diminished capacitance $[9,11]$. For this reason, some CDI unit cells add a conductive material to the composition of the CDI electrode, such as carbon black or graphite [12-14].

In this present study we prepared a reduced graphene oxide (RGO) and used it as a conductive material to improve the performance of electrodes made from $\mathrm{AC}$ powder and polymer binder for CDI application. The salt removal performance of RGO was compared with graphite, which is a common conductive material for CDI.

\section{Experimental}

\subsection{Synthesis of RGO}

GO was prepared using a modification of Hummers method [15]. Graphite flakes (Timrex, Timcal Ltd.) were added and stirred in a mixture of 2:1 $\mathrm{HNO}_{3}$ (Junsei Chemical Ltd.) and $\mathrm{H}_{2} \mathrm{SO}_{4}$ (Junsei Chemical Ltd.). After that, the mixture was diluted with water at room temperature and left overnight. The mixture was filtered and dried in ambient conditions for 24 h. Later, $\mathrm{KMnO}_{4}$ (Junsei Chemical Ltd.) was added slowly to a reaction vessel with concentrated $\mathrm{H}_{2} \mathrm{SO}_{4}$ in an ice bath and the mixture was stirred for $2 \mathrm{~h}$. After dilution with water, $\mathrm{H}_{2} \mathrm{O}_{2}$ (Dongwoo Fine-Chem) was added to the mixture in an ice bath. Finally the mixture was centrifuged and washed with $\mathrm{HCl}$ aqueous solution (Junsei Chemical Ltd.) to remove residual ions and then washed with water until its $\mathrm{pH}$ reached 7. $\mathrm{GO}$ was reduced by heat treatment to $400^{\circ} \mathrm{C}$, followed by a rapid heating process for graphene exfoliation to $900^{\circ} \mathrm{C}$. Constant heating at $900^{\circ} \mathrm{C}$ was maintained for $2 \mathrm{~h}$ and the RGO sample was obtained.

\subsection{Characterization}

The morphology of samples was characterized by using scanning electron microscope (SEM, S-4700, Hitachi). The specific surface areas and pore parameters were obtained by analyzing nitrogen adsorption-desorption isotherms, recorded at $77 \mathrm{~K}$ using a surface area analyzer (BELSORP-mini, BEL Japan Inc.). Prior to this measurement, the samples were degassed at $250^{\circ} \mathrm{C}$ for $2 \mathrm{~h}$. The specific surface area and the pore size were analyzed using the Brunauer-EmmettTeller (BET) method and the Barrett-Joyner-Halenda (BJH) method, respectively. X-ray diffraction (XRD, RINT2000, Rigaku) was carried out to investigate the graphitic structure of graphite, GO, and RGO. Scans were done for $2 \theta$ values between 5 and $80^{\circ}$ at $0.02^{\circ} / \mathrm{min}$.

\subsection{Fabrication of CDI electrodes}

The carbon slurry for the electrodes was prepared by mixing AC (P-60 Kuraray Co., Ltd.) with PVdF (Sigma-Aldrich Co., Ltd.) which was dissolved in dimethylacetamide (DMAc, Sigma-Aldrich Co., Ltd.), and RGO as the conductive material, with the composition of $85 \%: 10 \%: 5 \%$, respectively. The mixture was stirred for $12 \mathrm{~h}$. The obtained carbon slurry was cast into a graphite sheet using a doctor blade, for use as a current collector. The total thickness of the electrode was $400 \mu \mathrm{m}$. The cast electrode was dried in a vacuum oven at $70^{\circ} \mathrm{C}$ for two hours. The AC-RGO electrode was obtained by cutting the cast electrode into a piece $10 \times 10 \mathrm{~cm}^{2}$ with an additional area $(3 \times$ $5 \mathrm{~cm}^{2}$ ) left for a connectivity space. A hole with a diameter of 8 $\mathrm{mm}$ was made for electrolyte flow in the middle of the electrode. For comparison, we also made an electrode with graphite as the conductive material (AC-Gr) with the same composition as ACRGO. An electrode with no added conductive material (AC) was also made, with the composition of $\mathrm{AC}$ and $\mathrm{PVdF}$ of $85 \%$ and 15 $\%$ respectively. The morphologies of the fabricated electrodes were observed with a SEM (S-4700, Hitachi).

\subsection{Electrochemical characterization}

Cyclic voltammetry (CV) using a three electrode system was conducted to measure the capacitance behavior of the carbon electrodes. CV was performed with an AutoLab PGST30 potentiostat. A polarized electrode with the same composition as the CDI electrode was used as a working electrode. A platinum electrode and $\mathrm{Ag} / \mathrm{AgCl}$ electrode were used as the counter and reference electrode, respectively. The electrolyte solution was $0.5 \mathrm{M} \mathrm{NaCl}$, and all tests were performed at $35^{\circ} \mathrm{C}$ in a water bath. The measurements were performed in the potential range of -0.2 to $0.8 \mathrm{~V}$ and measured at the sweep rate of 5,10,20,50, and $100 \mathrm{mV} / \mathrm{s}$.

Electric impedance spectroscopy (EIS) using a two electrode system was conducted to determine the internal resistance of the electrodes. The impedance measurement was conducted using the IM6ex spectroscope (Zahner Messtechnnik). A given potential of $0.0 \mathrm{~V}$ was applied to the electrode with $\mathrm{AC}$ potential amplitude of $10 \mathrm{mV}$ for a short time until the system stabilized. After giving $10 \mathrm{~mA}$ applied current to the electrodes with $10 \mathrm{mV}$ potential amplitude, the changes in resistance of the electrodes were measured in the frequency range of $0.1 \mathrm{~Hz}-100 \mathrm{kHz}$.

\subsection{Desalination performance test}

The desalination test of the CDI unit cell was performed in a continuous flow-through system as shown in Fig. 1. NaCl solution was pumped by a peristaltic pump and passed through the unit cell. A given potential was applied to the cell using a potentiostat (WPG100, WonATech Co., Ltd.). The conductivity of the effluent was measured using a $\mathrm{pH}$-conductivity meter (Sevenmulti, Mettler Toledo) and was converted to the concentration $(\mathrm{mg} / \mathrm{L})$.

The desalination comparison tests between AC-RGO, AC-Gr, and $\mathrm{AC}$ electrodes were conducted with the following conditions. The applied voltage was 1.0 and $1.5 \mathrm{~V}$ for adsorption and $0.0 \mathrm{~V}$ for desorption, where both were performed for $3 \mathrm{~min}$ and repeated for 5 cycles. $\mathrm{NaCl} 250 \mathrm{mg} / \mathrm{L}$ was used as the feed solution with a feed rate of 20 and $30 \mathrm{~mL} / \mathrm{min}$. 


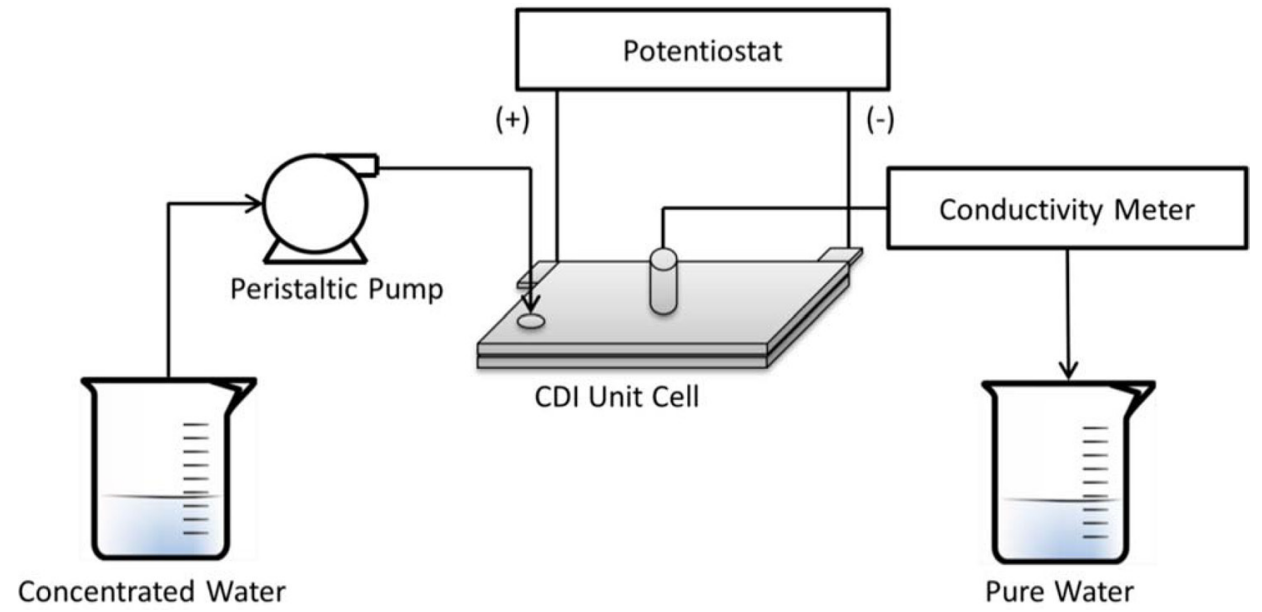

Fig. 1. Scheme of desalination performance test. CDI: capacitive deionization.
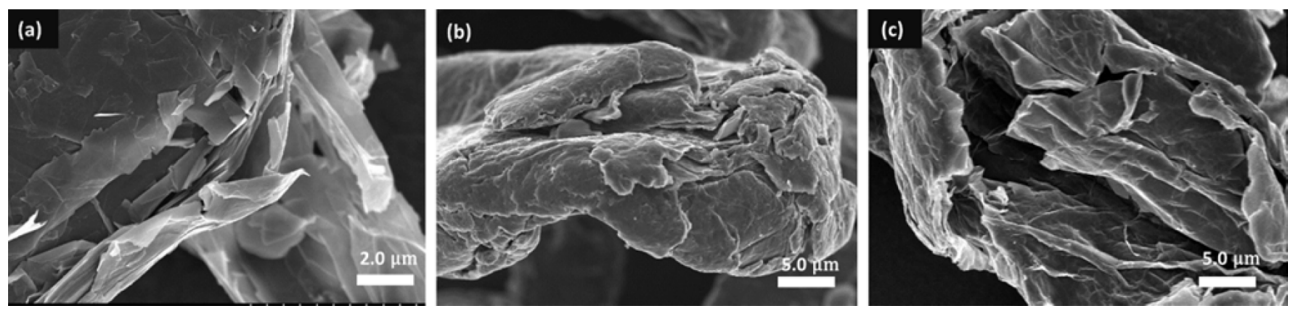

Fig. 2. Scanning electron microscope images of materials: (a) graphite (b) graphite oxide (GO) (c) reduced GO.

\section{Results and Discussion}

\subsection{Characterization of RGO}

The morphologies of the obtained RGO were observed and compared with the graphite and GO by SEM, and these SEM images of graphite, GO, and RGO material are shown in Figs. 2a-c respectively. GO can be obtained by modification of Hummers method [15] which changes the highly crystalline layered graphite structure shown in Fig. 2a into an exfoliated structure (Fig. 2b). The surfaces of GO sheets have a soft morphology which may be due to the hydroxyl and carboxyl functional group that are attached to GO. The reduction of GO that was performed to $400^{\circ} \mathrm{C}$ removes these functional groups from the $\mathrm{GO}$ structure and the following rapid heating process up to $900^{\circ} \mathrm{C}$ exfoliated the GO into single layers of graphite. As shown in Fig. 2c, wrinkle morphology is observed in the RGO structure which is probably due to the removal of carbon atoms in the form of carbon dioxide, which leads to lattice defects throughout the sheets [16]. The single layer of graphite has been known to have high electric conductivity $[16,17]$, thus its addition to the carbon electrode compositions will improve the electrode's conductivity and ability to adsorb the charged ions for CDI.

The structural changes of graphite, GO, and RGO were investigated by XRD measurement, and the patterns are shown in Fig. 3 . The XRD pattern of graphite shows one strong and sharp peak at $2 \theta=26.4^{\circ}$ which corresponds to an interlayer distance $\left(\mathrm{d}_{002}\right)$ of $3.38 \AA$. After thermal treatment, this peak was markedly shifted to

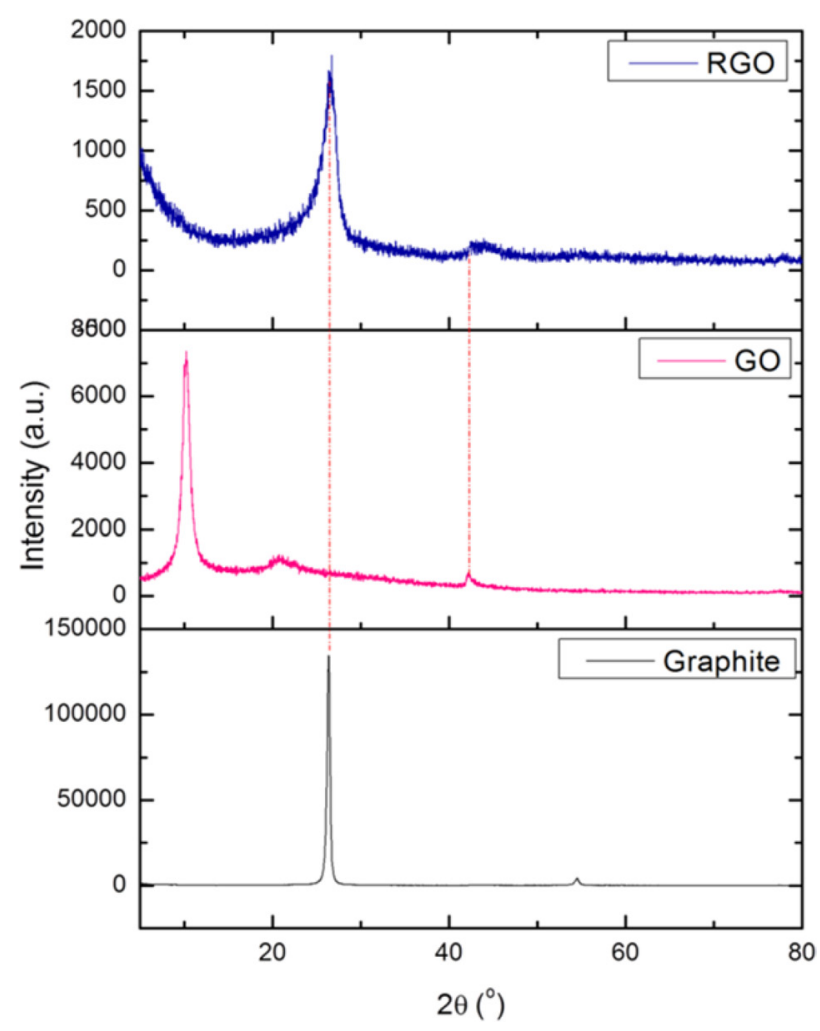

Fig. 3. X-ray diffraction patterns of graphite, graphite oxide (GO), and reduced GO (RGO). 
Table 1. BET properties of RGO and graphite

\begin{tabular}{cccc} 
& $\begin{array}{c}\text { SBET } \\
\left(\mathrm{m}^{2} / \mathrm{g}\right)\end{array}$ & $\begin{array}{c}\mathrm{V}_{\text {total }} \\
\left(\mathrm{cm}^{3} / \mathrm{g}\right)\end{array}$ & $\begin{array}{c}\text { d-pore } \\
(\mathrm{nm})\end{array}$ \\
\hline RGO & 41.96 & 0.07 & 7.07 \\
Graphite & 24.06 & 0.05 & 8.98 \\
\hline
\end{tabular}

BET: Brunauer-Emmett-Teller, RGO: reduced graphene oxide.
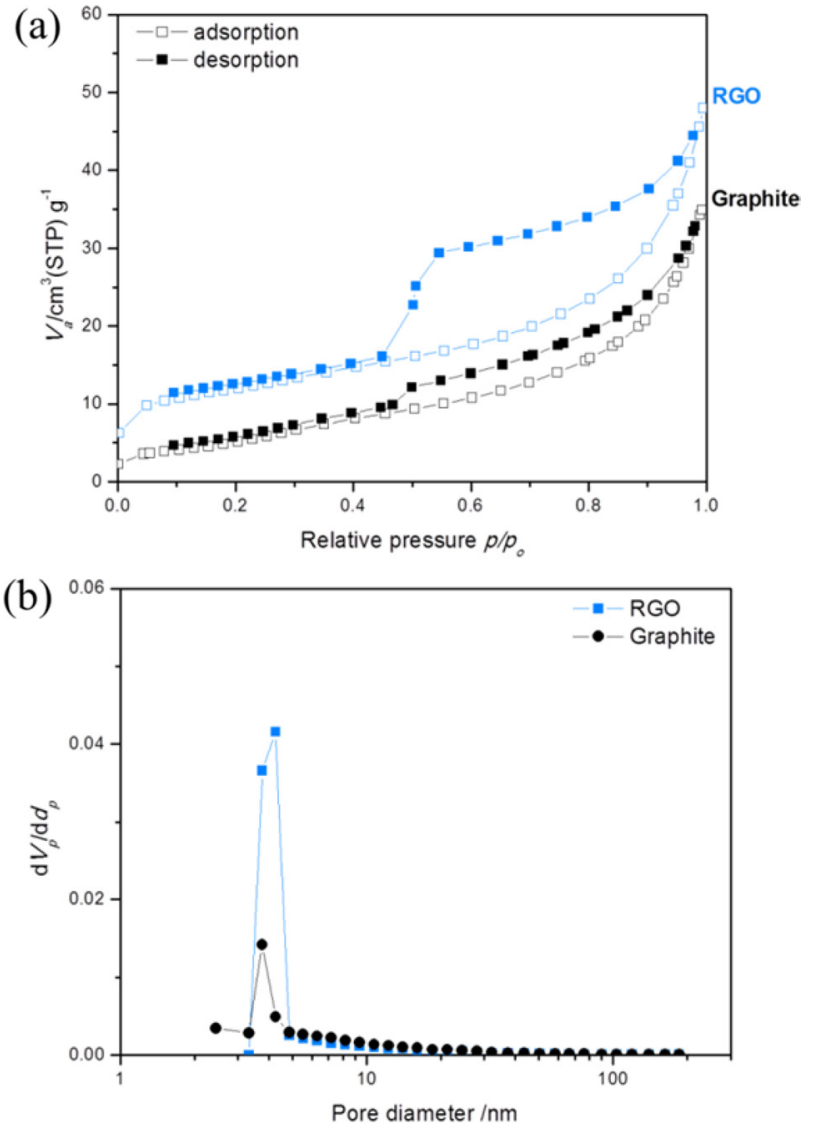

Fig. 4. (a) Nitrogen adsorption-desorption isotherms for reduced graphite oxide (RGO) and graphite (b) Barrett-Joyner-Halenda pore-size distribution curves.

a point of $2 \theta=10.24^{\circ}$ and the interlayer distance expanded to 8.64 $\AA$. The larger interlayer distance is due to the oxidation of graphite into GO with the formation of hydroxyl and carboxyl groups. The reduction process was expected to contract the interlayer of the GO and remove the functional groups, leading to the exfoliation of the GO layer to produce a single layer of graphite. After the thermal treatment of GO, the peak was similar to that of graphite, which is at the point of $2 \theta=26.76^{\circ}$ and the interlayer distance was reduced to $3.33 \AA$. This re-shifted peak shows that the functional groups in the GO interlayer were removed and the layers were exfoliated. The calculation of the RGO peak using the Debye-Scherrer equation gives about 12-13 layers in a single sheet.

Table 1 summarizes the BET surface areas, total pore volumes, and average pore sizes of synthesized RGO and graphite for comparison. The $\mathrm{N}_{2}$ adsorption-desorption isotherm as well
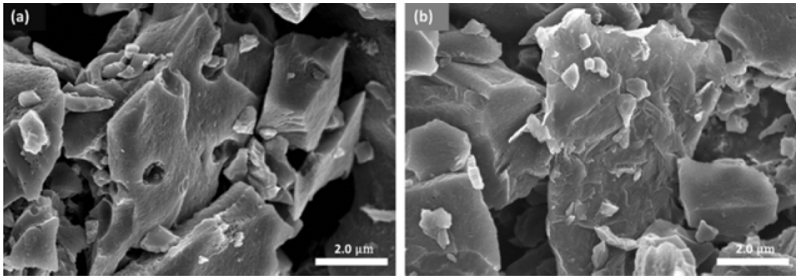

Fig. 5. Scanning electron microscope images of electrodes: (a) activated carbon (AC) (b) AC- reduced graphite oxide.

Table 2. BET properties of the AC, AC-RGO, and AC-Gr elec-

trodes

\begin{tabular}{cccc} 
& $\begin{array}{c}\mathrm{S}_{\mathrm{BET}} \\
\left(\mathrm{m}^{2} / \mathrm{g}\right)\end{array}$ & $\begin{array}{c}\mathrm{V}_{\text {total }} \\
\left(\mathrm{cm}^{3} / \mathrm{g}\right)\end{array}$ & $\begin{array}{c}\text { d-pore } \\
(\mathrm{nm})\end{array}$ \\
\hline $\mathrm{AC}$ & 1805.6 & 0.93 & 2.06 \\
$\mathrm{AC}-\mathrm{RGO}$ & 1556.8 & 0.72 & 1.84 \\
$\mathrm{AC}-\mathrm{Gr}$ & 1528.8 & 0.69 & 1.82 \\
\hline
\end{tabular}

BET: Brunauer-Emmett-Teller, AC: activated carbon, RGO: reduced graphene oxide.

as pore size distribution is shown in Fig. 4. The BET surface area and total pore volume of RGO are slightly larger than graphite due to the thermal exfoliation. However, the surface area of the synthesized RGO in this experiment is still below the theoretical value of the fully exfoliated pristine graphene, which might be due to the incomplete exfoliation of GO. Based on pore width, the RGO and graphite consist of mesopores with pore diameters of 3-4 nm, which was suitable for access by ions.

\subsection{Characterization of AC-RGO electrode}

Fig. 5 shows SEM images of the AC and AC-RGO electrodes. The AC electrodes provide a large number of micropores (Fig. 5a) to accommodate the charged ions to be adsorbed, yet strong aggregation between $\mathrm{AC}$ particles resulted in poor conductivity. For the AC-RGO electrode (Fig. 5b), RGO can act as a flexible bridge to form a "plane-to-point" (RGO to $\mathrm{AC}$ ) conducting network, which is beneficial for decreasing the aggregation of AC particles and therefore enhances the pore availability [18].

Table 2 shows the BET surface area, total pore volume, and average pore diameter of the AC-RGO electrode compared with the $\mathrm{AC}$ electrode. The $\mathrm{AC}$ material provides high surface area as the main active material for electrosorption. With the addition of RGO in the electrode composition, the surface area and pore volume decrease as the RGO particles fill the path of the ions to be adsorbed. However, compared to the AC, which mainly consists of micropores, RGO can decrease the overlapping effect caused by micropores, which is beneficial to electrosorption. Hence, despite the decrease in surface area, the conductivity of electrode is also an important factor for the electrosorption capacity, and helps determine the flow of charged ions in the electrode pore. The movement of ions is more difficult in the smaller pores than in the large pores, so that RGO can provide micropores' accessibility to the salt solution [11]. 

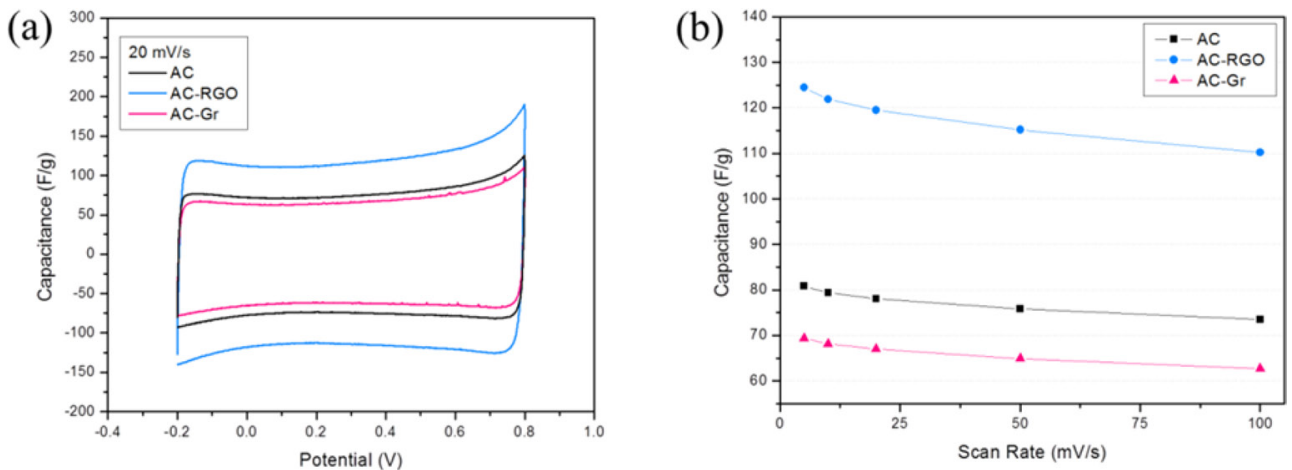

Fig. 6. (a) Cyclic voltammograms of activated carbon (AC), AC-reduced graphite oxide (RGO), and AC-Gr electrodes. (b) The specific capacitance of AC, AC-RGO, and AC-Gr electrodes at different sweep rates.
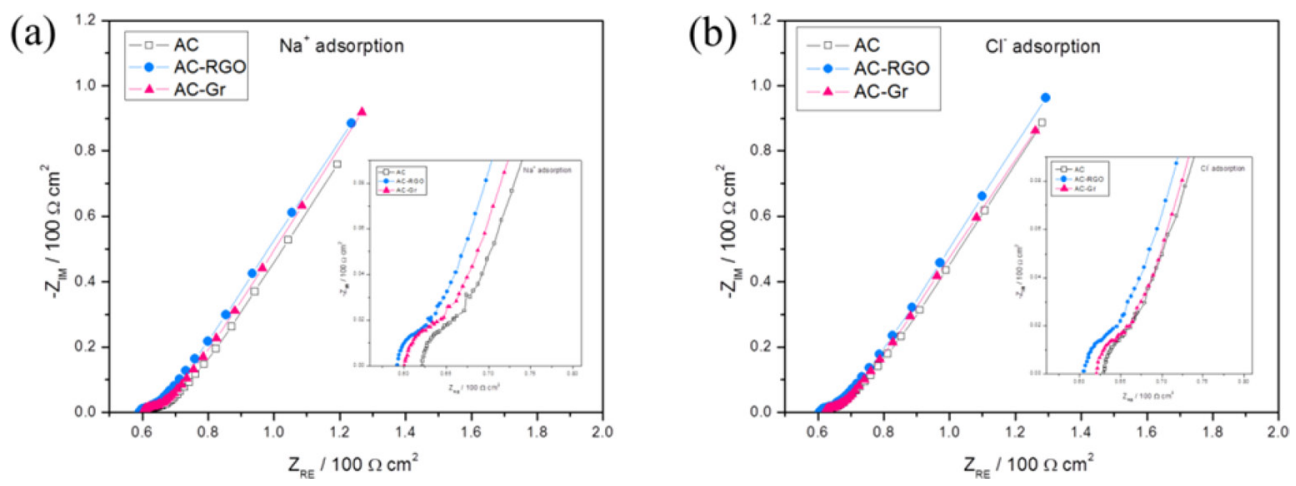

Fig. 7. Nyquist plots for the impedance response of the activated carbon (AC), AC-reduced graphite oxide (RGO), and AC-Gr electrodes in terms of (a) cation $\left(\mathrm{Na}^{+}\right)$adsorption $(b)$ anion $(\mathrm{Cl})$ adsorption.

\subsection{Electrochemical characterization}

$\mathrm{CV}$ measurements were carried out within the potential range of -0.2 to $0.8 \mathrm{~V}$ to analyze the electrochemical behavior of the $\mathrm{CDI}$ electrodes. Fig. 6a shows the cyclic voltammograms of AC$\mathrm{RGO}, \mathrm{AC}-\mathrm{Gr}$ and $\mathrm{AC}$ electrodes at a scan rate of $20 \mathrm{mV} / \mathrm{s}$. It can be seen that the samples show a typical rectangular curve within the potential ranges, indicating high electrosorption capacitive behavior. However, small distortions were also observed in the voltammogram, a delay of potential when reversing the potential sweep. This means that the electrochemical behavior of the CDI electrodes depends not only on the charging current in the electric double layer, but also on faradaic currents [19].

The electrodes' specific capacitances were calculated by using the following equation [20]:

$$
C(F / g)=\frac{\int_{0}^{t_{s}} i d t}{\int_{V_{1}}^{V_{2}} d V}\left(\frac{1}{m}\right)=\frac{\frac{1}{r_{s}} \int_{V_{1}}^{V_{2}} i d V}{\int_{V_{1}}^{V_{2}} d V}\left(\frac{1}{m}\right)=\frac{\left(1 / 2 r_{s}\right) S_{c}}{V_{2}-V_{1}}\left(\frac{1}{m}\right)
$$

where $t_{s}$ is the total one-way scan time (s), $r_{s}$ is the scan rate $(\mathrm{V} / \mathrm{s}), S_{c}$ is the area of the total charge i, $V$ is the potential (V), and $m$ is the mass of carbon (g). The specific capacitance of each electrode at the varying scan rate is shown in Fig 6b. AC-RGO has the largest specific capacitance of about $110-125 \mathrm{~F} / \mathrm{g}$, while for the $\mathrm{AC}$ and $\mathrm{AC}-\mathrm{Gr}$ it was $73-81$ and $63-70 \mathrm{~F} / \mathrm{g}$ respectively, depending on the potential scan rate. The specific capacitance of AC-RGO was increased compared with the AC electrode, indicating that the aggregation of $\mathrm{AC}$ particles can be decreased by adding a conductive material such as RGO. However, the addition of graphite reduced the specific capacitance of the electrode, perhaps due to the bulk filling of graphite in the AC electrode pores. This result shows that after the oxidation and thermal treatment of graphite, RGO can be used to increase the specific capacitance of AC electrodes.

EIS was also used to observe the electrochemical behavior of the CDI electrodes. The Nyquist plots and their enlarged sections (high frequency, inset) of the AC-RGO, AC-Gr, and AC electrodes are shown in Fig. 7. These plots show typical EDL capacitor behavior. The region with the $45^{\circ}$ slope at high frequencies $(10 \mathrm{kHz}-1 \mathrm{~Hz})$ can be assigned to the behavior of the porous structure and is often called the distributed resistance. For low frequencies $(<1 \mathrm{~Hz})$, the spectrum approaches a vertical line and behaves like an ideal capacitor, with $\mathrm{R}$ and $\mathrm{C}$ being no longer frequency-dependent [21].

The impedance performance from the high-frequency range, which is referred to as equivalent series resistance (ESR), is discussed here, as it is related to the electrode conductivity. By comparing the three samples in a single plot as in Fig. 7, it can be seen that the AC-RGO and AC-Gr electrodes have lower ESR than the AC electrode. This shows that the addition of a conductive material to the $\mathrm{AC}$ electrode reduces the electrode/ 

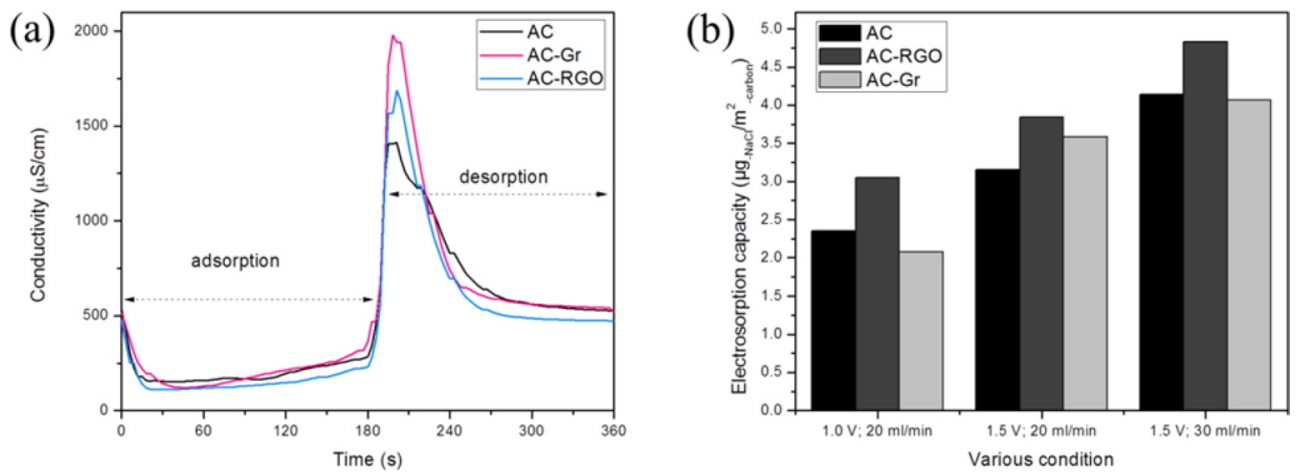

Fig. 8. (a) Conductivity changes per time of activated carbon ( $A C$ ), $A C$-reduced graphite oxide (RGO), and AC-Gr electrodes at 5 th cycle using $1.5 \mathrm{~V}$ applied voltage and $20 \mathrm{~mL} / \mathrm{min}$ feed rate. (b) The comparison of electrosorption capacity of AC, AC-RGO, and AC-Gr electrodes for various conditions.

electrolyte interface resistance, thus increasing the ability of the electrolyte solution to penetrate into the micropores of the AC particles.

Two kinds of Nyquist plot are shown in Figs. 7a and b, comparing the difference of the electrodes adsorption for cation $\left(\mathrm{Na}^{+}\right)$and anion $\left(\mathrm{Cl}^{-}\right)$, respectively. There is not much difference between them, just the ESR for the $\mathrm{Na}^{+}$adsorption is slightly lower than the ESR for the $\mathrm{Cl}^{-}$, due to the difference in ion size.

\subsection{Desalination performance test}

The desalination performance test was carried out with adsorption ( $1.5 \mathrm{~V}$ for $3 \mathrm{~min})$ and desorption $(0.0 \mathrm{~V}$ for $3 \mathrm{~min})$ processes with a $\mathrm{NaCl}$ feed rate of $20 \mathrm{~mL} / \mathrm{min}$, repeated for five cycles. The results of conductivity change per unit time at the 5 th cycle for AC-RGO, AC-Gr, and AC are shown in Fig. 8a. The initial conductivity was $512 \mu \mathrm{S} / \mathrm{cm}$ based on the conductivity of the $250 \mathrm{mg} / \mathrm{L} \mathrm{NaCl}$ solution. When the potential was applied to the electrode, $\mathrm{Na}^{+}$and $\mathrm{Cl}^{-}$were attracted onto the surface of the oppositely charged electrodes, which can be observed from the decreasing conductivity of the $\mathrm{NaCl}$ solution. The AC-RGO electrode reduced the conductivity of the $\mathrm{NaCl}$ solution more than the AC-Gr and AC electrodes, which means relatively more ions were being adsorbed in the AC-RGO electrodes' pores. The conductivity of $\mathrm{NaCl}$ was also reduced using the AC-Gr electrode. However after it reached the lowest point, the conductivity increased gradually. This can be explained because the capacitance of the AC-Gr electrode was the lowest.

The electrosorption capacity of the electrodes was calculated using the following equation:

$$
\begin{aligned}
& \text { electrosorption capacity } \\
& \left(\frac{m g-N a C l}{g-\text { carbon }}\right)=\frac{c_{i} \cdot V \times\left(\frac{\left(C_{i} \cdot t\right)-\int c_{e f f} d t}{\left(C_{i} \cdot t\right)}\right)}{m}
\end{aligned}
$$

where $C_{i}$ is the influent concentration of the salt solution $(\mathrm{mg} / \mathrm{L})$, $V$ is the total volume of feed solution (L), $t$ is the adsorption time (s), $C_{e f f}$ is the effluent concentration from the 5 th cycle $(\mathrm{mg} / \mathrm{L})$, and $m$ is the amount of carbon used (g). The concentration of the solution was determined by converting the conductivity. Comparisons of the electrosorption capacity of the AC-RGO, AC-Gr, and $\mathrm{AC}$ electrodes at various conditions is shown in Fig. 8b. The AC-RGO electrode shows the greatest improvement of electrosorption capacity from the $\mathrm{AC}$ electrode in every condition of the performance test. In comparison, the AC-Gr electrode shows improvement only at the higher voltage and lower solution feed rate. These results show that RGO can be effectively used as the conductive material for CDI electrodes rather than graphite.

\section{Conclusions}

RGO was synthesized and added as a conductive material in the composition of a carbon electrode for application in CDI. The electrochemical behavior of the AC-RGO electrode showed that it can increase the specific capacitance and reduce the ESR of an AC electrode, and indicated that RGO reduced the aggregation of $\mathrm{AC}$ particles, thus improving the penetration of electrolyte solution into the micropores of AC particles. The salt removal efficiency and the electrosorption capacity of the AC-RGO electrode was higher than the AC-Gr in every condition performed in this experiment, which proves that RGO is preferred over graphite as a conductive material addition for CDI applications.

\section{Acknowledgements}

This work was supported by the Innopolis Commercialization of Technology Development Project (Establishment of KIERKyushu University R\&D Center and Development of Nano-Carbon Composite Electrode for CDI) funded by the INNOPOLIS Foundation in the Republic of Korea.

\section{References}

[1] Welgemoed TJ, Schutte CF. Capacitive Deionization Technology ${ }^{\mathrm{TM}}$ : an alternative desalination solution. Desalination, 183, 327 (2005). http://dx.doi.org/10.1016/j.desal.2005.02.054

[2] Zou L, Morris G, Qi D. Using activated carbon electrode in electrosorptive deionisation of brackish water. Desalination, 225, 329 (2008). http://dx.doi.org/10.1016/j.desal.2007.07.014.

[3] Oren Y. Capacitive deionization (CDI) for desalination and water 
treatment--past, present and future (a review). Desalination, 228 , 10 (2008). http://dx.doi.org/10.1016/j.desal.2007.08.005.

[4] Farmer JC, Fix DV, Mack GV, Pekala RW, Poco JF. Capacitive deionization of $\mathrm{NaCl}$ and $\mathrm{NaNO}_{3}$ solutions with carbon aerogel electrodes. J Electrochem Soc, 143, 159 (1996). http://dx.doi. org/10.1149/1.1836402.

[5] Hou CH, Huang CY. A comparative study of electrosorption selectivity of ions by activated carbon electrodes in capacitive deionization. Desalination, 314, 124 (2013). http://dx.doi.org/10.1016/j. desal.2012.12.029.

[6] Oh HJ, Lee JH, Ahn HJ, Jeong Y, Kim YJ, Chi CS. Nanoporous activated carbon cloth for capacitive deionization of aqueous solution. Thin Solid Films, 515, 220 (2006). http://dx.doi.org/10.1016/j. tsf.2005.12.146

[7] Yang J, Zou L, Choudhury NR. Ion-selective carbon nanotube electrodes in capacitive deionisation. Electrochim Acta, 91, 11 (2013). http://dx.doi.org/10.1016/j.electacta.2012.12.089.

[8] Zhan Y, Nie C, Li H, Pan L, Sun Z. Enhancement of electrosorption capacity of activated carbon fibers by grafting with carbon nanofibers. Electrochim Acta, 56, 3164 (2011). http://dx.doi. org/10.1016/j.electacta.2011.01.059.

[9] Kurzweil P. Electrochemical double-layer capacitors: Carbon material. In: Batteries and supercapacitors, Elsevier, 821 (2009).

[10] Qu D, Shi H. Studies of activated carbons used in double-layer capacitors. J Power Sources, 74, 99 (1998). http://dx.doi.org/10.1016/ s0378-7753(98)00038-X.

[11] Frackowiak E, Béguin F. Carbon materials for the electrochemical storage of energy in capacitors. Carbon, 39, 937 (2001). http:// dx.doi.org/10.1016/s0008-6223(00)00183-4.

[12] Nadakatti S, Tendulkar M, Kadam M. Use of mesoporous conductive carbon black to enhance performance of activated carbon electrodes in capacitive deionization technology. Desalination, 268,
182 (2011). http://dx.doi.org/10.1016/j.desal.2010.10.020

[13] Li H, Zou L, Pan L, Sun Z. Novel graphene-like electrodes for capacitive deionization. Environ Sci Technol, 44, 8692 (2010). http:// dx.doi.org/10.1021/es101888j.

[14] Park KK, Lee JB, Park PY, Yoon SW, Moon JS, Eum HM, Lee CW. Development of a carbon sheet electrode for electrosorption desalination. Desalination, 206, 86 (2007). http://dx.doi.org/10.1016/j desal.2006.04.051.

[15] Hummers WS, Jr., Offeman RE. Preparation of graphitic oxide. J Am Chem Soc, 80, 1339 (1958). http://dx.doi.org/10.1021/ ja01539a017.

[16] Pei S, Cheng HM. The reduction of graphene oxide. Carbon, 50, 3210 (2012). http://dx.doi.org/10.1016/j.carbon.2011.11.010.

[17] Shin HJ, Kim KK, Benayad A, Yoon SM, Park HK, Jung IS, Jin MH, Jeong HK, Kim JM, Choi JY, Lee YH. Efficient reduction of graphite oxide by sodium borohydride and its effect on electrical conductance. Adv Funct Mater, 19, 1987 (2009). http://dx.doi org/10.1002/adfm.200900167.

[18] Li H, Pan L, Nie C, Liu Y, Sun Z. Reduced graphene oxide and activated carbon composites for capacitive deionization. J Mater Chem, 22, 15556 (2012). http://dx.doi.org/10.1039/c2jm32207b.

[19] Choi JY, Choi JH. A carbon electrode fabricated using a poly(vinylidene fluoride) binder controlled the Faradaic reaction of carbon powder. J Ind Eng Chem, 16, 401 (2010). http://dx.doi. org/10.1016/j.jiec.2009.08.005.

[20] Tashima D, Yoshitama H, Otsubo M, Maeno S, Nagasawa Y. Evaluation of electric double layer capacitor using Ketjenblack as conductive nanofiller. Electrochim Acta, 56, 8941 (2011). http:// dx.doi.org/10.1016/j.electacta.2011.07.124

[21] Kötz R, Hahn M, Gallay R. Temperature behavior and impedance fundamentals of supercapacitors. J Power Sources, 154, 550 (2006). http://dx.doi.org/10.1016/j.jpowsour.2005.10.048. 